\title{
Gene expression alterations in the non-neoplastic parenchyma adjacent to infiltrating pancreatic ductal adenocarcinoma
}

\author{
Noriyoshi Fukushima ${ }^{1}$, Jens Koopmann ${ }^{1}$, Norihiro Sato ${ }^{1}$, Nijaguna Prasad ${ }^{2}$, \\ Ralph Carvalho ${ }^{1,5}$, Steven D Leach ${ }^{2}$, Ralph H Hruban ${ }^{1,3}$ and Michael Goggins ${ }^{1,3,4}$
}

${ }^{1}$ Department of Pathology, The Johns Hopkins Medical Institutions, Baltimore, MD, USA; ${ }^{2}$ Department of Surgery, The Johns Hopkins Medical Institutions, Baltimore, MD, USA; ${ }^{3}$ Department of Oncology, The Johns Hopkins Medical Institutions, Baltimore, MD, USA; ${ }^{4}$ Department of Medicine, The Johns Hopkins Medical Institutions, Baltimore, MD, USA and ${ }^{5}$ Department of Pathology, Academisch Medisch Centrum, Amsterdam, The Netherlands

\begin{abstract}
The non-neoplastic pancreatic parenchyma adjacent to infiltrating ductal adenocarcinoma demonstrates inflammation, fibrosis, acinar cell loss and small duct-like metaplasia of acinar cells. Similar morphologic changes are also observed in the setting of chronic pancreatitis. In addition, peritumoral acini have been shown to have alterations in gene expression even in the absence of morphological changes. To better understand the pancreatic acinar responses to infiltrating pancreatic ductal adenocarcinoma, we characterized gene expression patterns of pancreatic acinar tissue adjacent to infiltrating pancreatic ductal adenocarcinomas and compared them to gene expression patterns of acinar tissue affected by chronic pancreatitis as well as to those of normal pancreatic acini. Fresh-frozen pancreatic acinar tissue was microdissected from nine patients (three with pancreatic cancer, three with chronic pancreatitis, three with normal pancreata) using laser capture microdissection, and extracted RNA from each microdissection was subjected to two rounds of linear amplification and hybridized to oligonucleotide microarrays. Gene expression patterns were confirmed using quantitative RT-PCR and/or immunohistochemistry. A total of 20 genes was found to be overexpressed in peritumoral acinar tissue compared to normal acinar tissue and to acini affected by chronic pancreatitis. These 20 genes included pancreatitis-associated protein (HIP/PAP), a gene known to be overexpressed in acini adjacent to infiltrating pancreatic cancer, and the gene cartilage glycoprotein-39 (HC gp-39 or TKL-40). Serum HC gp-39 protein levels were significantly higher in patients with pancreatic cancer and in those with chronic pancreatitis than in controls without pancreatic disease. There was no significant difference in the levels of serum HC gp-39 in patients with pancreatic cancer and those with chronic pancreatitis. Our results demonstrate some of the molecular alterations in acinar cells that occur in response to adjacent infiltrating pancreatic ductal adenocarcinoma and reveal that such alterations can provide a rich source of markers of pancreatic cancer. Modern Pathology (2005) 18, 779-787, advance online publication, 25 March 2005; doi:10.1038/modpathol.3800337
\end{abstract}

Keywords: gene expression; parenchyma; ductal adenocarcinoma; pancreas

Pancreatic ductal carcinoma carries an extremely poor prognosis. Most patients are diagnosed at an advanced stage of the disease, and the incidence and mortality rates for invasive pancreatic cancer are almost identical. ${ }^{1}$ Infiltrating pancreatic ductal adenocarcinomas are associated with a prominent

Correspondence: Dr M Goggins, MD, Department of Pathology, Medicine, and Oncology, The Johns Hopkins Medical Institutions, 632 Ross Building, 720 Rutland Ave, Baltimore, MD 212052196, USA.

E-mail: mgoggins@jhmi.edu

Received 25 May 2004; revised and accepted 11 October 2004; published online 25 March 2005 non-neoplastic desmoplastic response involving multiple cell types including fibroblasts, inflammatory cells, and endothelial cells. Non-neoplastic acinar cells and islet cells of the pancreatic parenchyma adjacent to the infiltrating ductal adenocarcinoma can be altered in response to the invasive cancer and may show an inflammatory infiltrate, enlargement of the islets of Langerhans, and duct-like metaplasia of acinar cells. ${ }^{2,3}$ Some of the pathological features of the pancreatic parenchyma in this setting are similar to those found in chronic pancreatitis, including marked fibrosis and loss of acinar cells. Necrosis of the parenchyma is not usually seen in either pancreatic cancer or in 
chronic pancreatitis, but does occur in severe acute pancreatitis. ${ }^{4}$ In addition to obvious microscopic changes, there can also be a significant change in gene expression patterns in the pancreatic parenchyma. In fact, several genes overexpressed in pancreatic cancer tissues are derived from peritumoral tissues. ${ }^{2,5} \mathrm{~A}$ better understanding of the peritumoral alterations in pancreatic cancer may not only provide insights into the biology of pancreatic cancer but could also lead to the identification of novel tumor markers with diagnostic applications. For example, proteomics profiling of pancreatic juice identified elevated levels of pancreatitisassociated protein, PAP (also known as hepatocarcinoma-intestine-pancreas, HIP) in the pancreatic juice of patients with pancreatic cancer compared to those with benign pancreatic diseases. The source of HIP/PAP elevations was its overexpression in the pancreatic acinar cells adjacent to the infiltrating adenocarcinoma. ${ }^{6}$ The identification of a marker of pancreatic cancer arising from the non-neoplastic compartment raises the possibility that other proteins produced by pancreatic parenchymal cells adjacent to infiltrating adenocarcinomas could be used as diagnostic markers of pancreatic ductal adenocarcinoma.

In this study, we characterized the global gene expression patterns of pancreatic non-neoplastic tissues adjacent to infiltrating pancreatic ductal adenocarcinomas using laser capture microdissection and oligonucleotide microarrays and compared them to the gene expression profiles of normal pancreatic parenchyma and to those of the pancreatic parenchyma found in chronic pancreatitis.

\section{Materials and methods}

\section{Pancreatic Tissues and Serum Samples}

Fresh-frozen tissues and serum samples analyzed in this study were obtained from patients attending the Johns Hopkins Hospital with the approval of the Johns Hopkins Committee for Clinical Investigation. Pancreatic cancers and normal pancreatic tissues from surgically resected samples were stored at the Johns Hopkins University, Department of Pathology Tumor Bank at $-70^{\circ} \mathrm{C}$ for 1 to 8 years. Serial frozen section slides of microdissected specimens were used for immunohistochemistry.

Initially, serum samples were collected preoperatively from patients diagnosed with pancreatic cancer $(n=40$, mean 64 years old), those with chronic pancreatitis who were undergoing endoscopic evaluation of their disease $(n=28$, mean 56 years old), and patients without pancreatic disease who were undergoing evaluation for other benign gastrointestinal diseases such as choledochal cyst, gastritis, and abnormal liver function tests $(n=18$, mean 53 years old). All serum samples were stored at $-70^{\circ} \mathrm{C}$ until analysis. Levels of HC gp-39 (YKL-40) were measured in preoperative serum from a second group of 50 patients with pancreatic ductal adenocarcinoma (mean age, $67 \pm 10$ years) as well as from 50 patients with chronic pancreatitis (mean age, $57 \pm 14$ years), 25 of whom were undergoing endoscopic evaluation of their pancreatitis and 25 of whom were undergoing endoscopic assessment of their pancreatitis and 50 age/sex-matched controls (mean age $61 \pm 9$ years).

\section{Laser Capture Microdissection}

Nine tissue samples were separately obtained using laser capture microdissection from frozen tissue sections: three pancreatic parenchymal tissue samples adjacent to each pancreatic cancer tissue (PC-parenchyma), three samples of parenchyma from pancreata with chronic pancreatitis (CP-parenchyma), and three normal-appearing pancreatic parenchymal tissues (NP-parenchyma) distant from pancreata affected by pancreatic ductal adenocarcinoma (Figure 1). The histological appearances of the
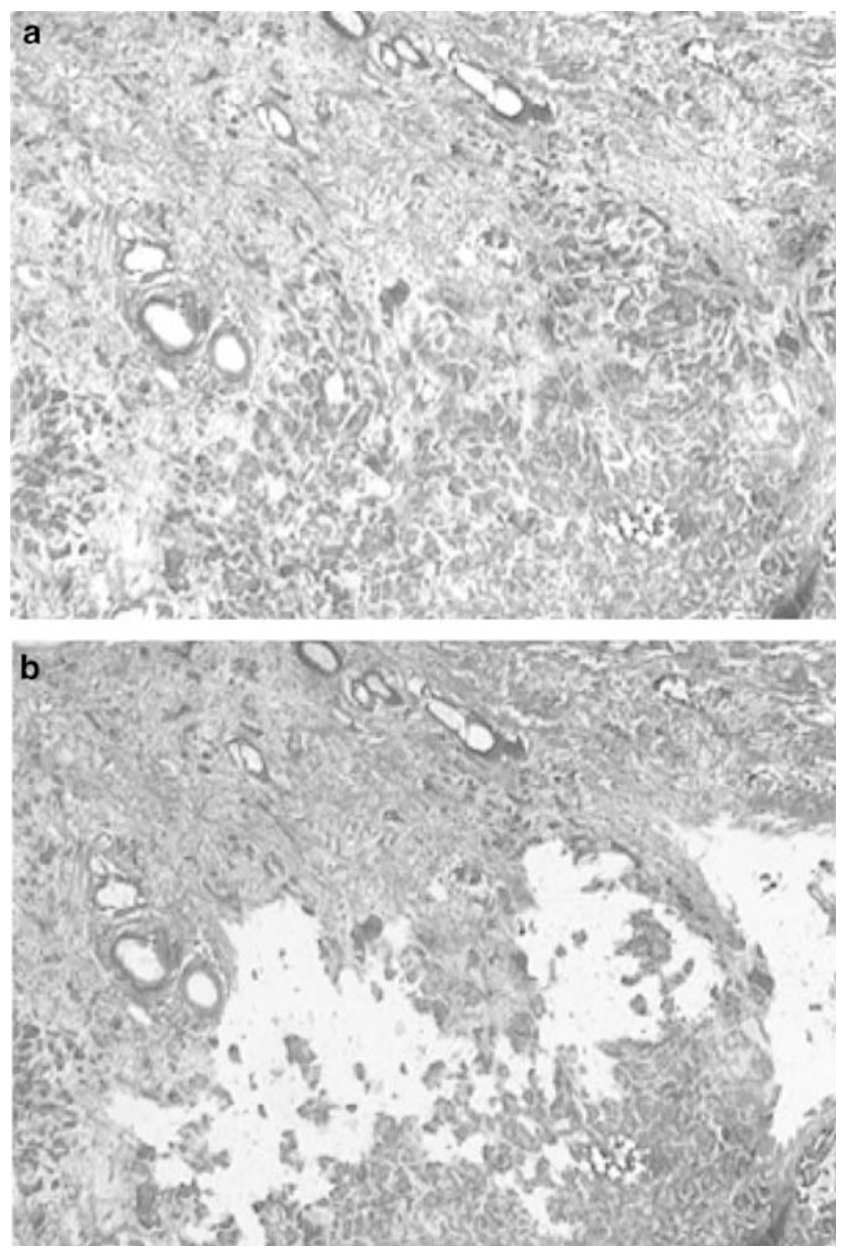

Figure 1 Laser capture microdissection. An example of laser capture microdissection. (a) A slide before microdissection showing invasive cancer with fibrosis in upper part and acinar tissue in lower part of the figure. (b) A slide after microdissection. Mainly atrophic acinar tissue facing cancer invasion was microdissected. 
microdissected, predominantly acinar tissues, from patients with pancreatic cancer and those with pancreatitis were similar. In particular, the pancreatitis tissues were not associated with marked inflammatory cell infiltration and the proportion of nonacinar cells was similar. The dissections were performed to obtain $\sim 1000$ predominantly peritumoral acinar cells (average \% of acinar cells, estimated at $85 \%$, range $70-90 \%$ ) including areas of atrophic acini and ductal metaplasia, but also included a small percentage of islet cells $(\sim 5 \%)$, as well as inflammatory cells (mainly lymphocytes) ( $\sim 5 \%)$, and fibroblasts $(\sim 5 \%)$ adjacent to infiltrating pancreatic cancer cells, with little or no fat $(<1 \%)$.

Frozen tissue sections $(8 \mu \mathrm{m})$ were cut and the slides were stored immediately at $-70^{\circ} \mathrm{C}$ until subsequent fixation. The first sections were labeled with H\&E and covered with a glass cover slip for diagnostic purposes. Tissue sections that underwent LCM were defrosted, fixed ( $70 \%$ ethanol for $3 \mathrm{~min}$ ), and dehydrated $(100 \%$ ethanol for $3 \mathrm{~min}$, xylene for $5 \mathrm{~min}$ ). Sections were dissected using a Pixcell II laser capture microdissection system (Arcturus Engineering Inc., Mountain View, CA, USA) with a $7.5-\mu \mathrm{m}$ in diameter laser beam (Figure 2). Generally, cells were obtained from about five serial sections of each case.

\section{RNA Extraction and Amplification}

Total RNA from microdissected tissues was extracted using the Picopure RNA isolation kit (Arcturus) according to the manufacturer's instructions. After determining RNA quality using RT-PCR amplification of glyceraldehyde-3-phosphate dehydrogenase (GAPDH), the extracted RNA was subjected to two rounds of linear amplification using the RiboAmp RNA amplification kit (Arcturus). On the second round of amplification, biotin labeling was performed with $10 \times$ biotin labeled Ribo from the Enzo ${ }^{\mathbb{R}}$ BioArray(tm) HighYield(tm) RNA Transcript Labeling Kit reagents (ENZO Life Science Inc., NY, USA) during the in vitro transcription (IVT) reaction of the RiboAmp Kit protocol. We performed this RNA amplification process using exactly the same IVT time ( $4 \mathrm{~h}$ on first round and $6 \mathrm{~h}$ on second round) and steps on all the samples to minimize the degradation bias of RNA.

\section{Oligonucleotide Array Hybridization and Data Analysis}

Sample preparation for array hybridization was made from $15 \mu \mathrm{g}$ of total RNA according to the manufacturer's instructions. The fragmented cRNA was hybridized to the Human Genome U133A chips (Affymetrix, Santa Clara, CA, USA) with 18462 unique gene/EST transcripts. The washing and staining procedure was performed in the Affymetrix

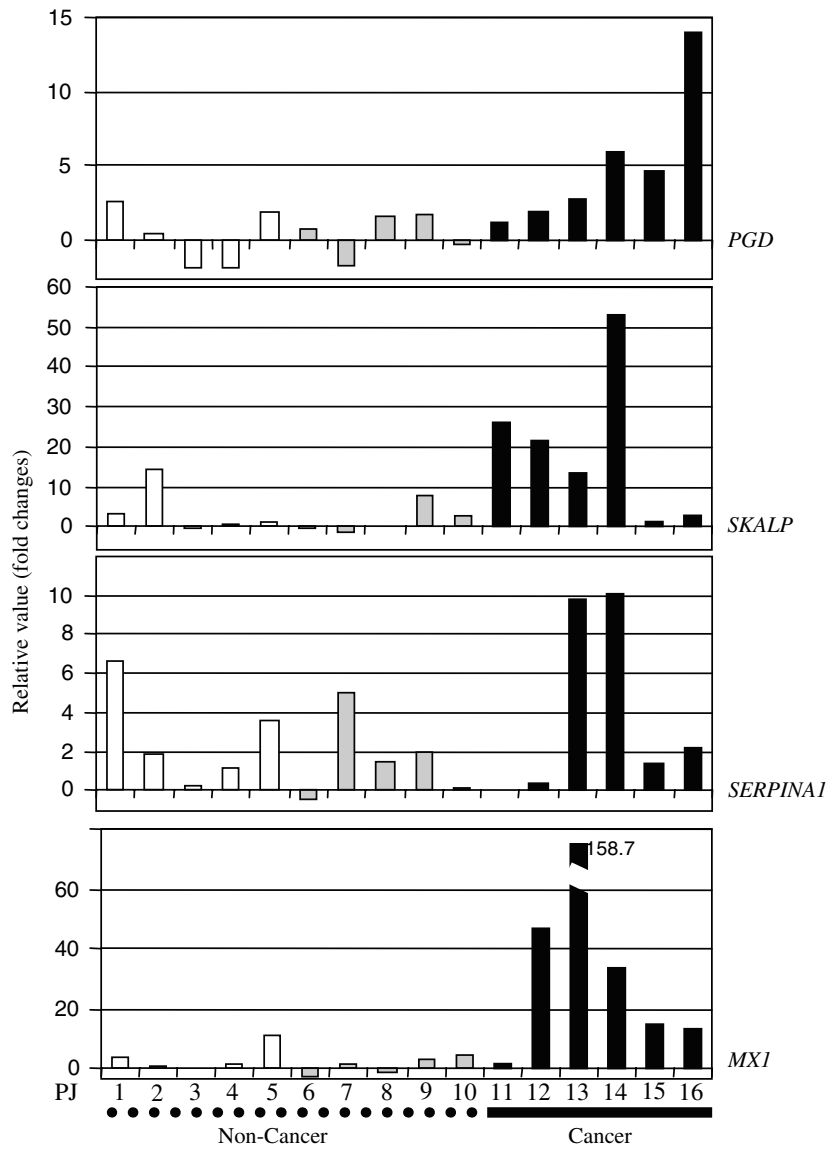

Figure 2 Quantitative RT-PCR. Results of quantitative RT-PCR analysis of four selected genes in NP-parenchyma, CP-parenchyma, and PC-parenchyma. Each bar represents a relative value of gene expression compared to those of normal pancreas samples $(n=3)$. The change in expression of each gene was normalized by $G A P D H$.

Fluidics Station according to the manufacturer's instructions. The probes were then scanned using a laser scanner, and signal intensity for each transcript (background-subtracted and adjusted for noise) was calculated using Microarray Suite Software 5.0 (Affymetrix). Fold-change analysis of signal intensities between each of the two groups was performed using Data Mining Tool software (Affymetrix).

\section{Immunohistochemistry}

To confirm protein overexpression and identify the localization of protein expression to the pancreatic parenchyma, immunohistochemistry was performed on fresh-frozen or formalin-fixed paraffin sections. In all, $5 \mu \mathrm{m}$ frozen sections stored in $-70^{\circ} \mathrm{C}$ were fixed with 70,95 , and $100 \%$ alcohol. Paraffin sections were deparaffinized using standardized methods. Antigen retrieval was performed on paraffin sections for $20 \mathrm{~min}$ in $100 \mathrm{mM}$ sodium citrate buffer ( $\mathrm{pH}$ 6.0) heated at $95^{\circ} \mathrm{C}$ in a steamer, followed by cooling off for $20 \mathrm{~min}$. After blocking endogenous 
peroxidase activity with a $3 \%$ aqueous $\mathrm{H}_{2} \mathrm{O}_{2}$ solution for $5 \mathrm{~min}$, the primary antibodies were incubated with the sections in a Dako automatic immunostainer. The primary antibodies used for immunohistochemistry were goat polyclonal antibody against Lactoferrin (C-15, Santa Cruz, CA, USA; dilution 1:500), Toll-like receptor 3 (TLR3, Q-18, Santa Cruz; dilution 1:200), Growth arrestspecific 1 (Gas 1, S-18, Santa Cruz; dilution 1:200), and YKL-40 (Quidel Corporation, San Diego, CA, USA; dilution 1:50). PAP (CRD) antibody was a gift from Laurence Christa (The Institut National de la Santé et de la Recherche Médicale U-370 and Liver Unit, Centre Hospitalier Universitaire Necker, 75015 Paris, France). For each case, a control slide was incubated, with Tris-buffered saline buffer substituted for the primary antibody. The HRPLINK + DAB + detection kit (Dako, Carpinteria, CA, USA) was used for the detection of the immunostaining. Sections were counterstained with hematoxylin.

\section{One-Step SYBR Green-Based Quantitative RT-PCR}

To confirm our microarray data, PAP, lactotransferrin (LTF), human cartilage glycoprotein-39 (HC-gp39), and complement component 4-binding protein, alpha (C4BPA) were selected from the list of overexpressed genes in PC-parenchyma. One-step SYBR Green-based RT-PCR amplification was performed in the ABI7700 quantitative PCR system (Applied Biosystem, Foster City, CA, USA). After optimization of each of the primer pairs, samples were assayed in a $50 \mu \mathrm{l}$ reaction mixture containing $2 \mu \mathrm{l}$ of sample RNA using the QuantiTect SYBR Green RT-PCR kit (Qiagen, Valencia, CA, USA). RT-PCR primers for HIP/PAP were 5'-GGTGAAGAG CATTGGTAACAG- $3^{\prime}$ (sense) and 5'-TAACCTCA CATTACAGTTATAATC- $3^{\prime}$ (antisense), for $L T F$ were $5^{\prime}$-CAGTGACCCTGA TCCTAAC-3' (sense) and 5'CAGCTTTGACTGAAATATTCATC-3' (antisense), for HC-gp39 were 5'-ATGCTCAACACACTCAA GAAC- $3^{\prime}$ (sense) and $5^{\prime}$-CCTTGATTAGGGTGG TAAAATG-3' (antisense), for C4BPA were $5^{\prime}$ GCTGTG GAAAGTCTCTGATC-3' (sense) and $5^{\prime}$ GTAAGCGTCTGAGTTGAATG-3' (antisense), and for GAPDH were 5'-CCTGACCTGCCGTCTA GAAAAA-3' (sense) and 5'-TGTCGCTGTTGAAGT CAGAGGA- $3^{\prime}$ (antisense).

The thermal profile for one-step SYBR Greenbased RT-PCR consisted of a $30-\mathrm{min}$ RT step at $50^{\circ} \mathrm{C}$ and $15 \mathrm{~min}$ of $\mathrm{Taq}$ polymerase activation at $95^{\circ} \mathrm{C}$, followed by 43 cycles of PCR at $95^{\circ} \mathrm{C}$ for $20 \mathrm{~s}$ (denaturation), $58^{\circ} \mathrm{C}$ for $30 \mathrm{~s}$ (annealing), and $72^{\circ} \mathrm{C}$ for $30 \mathrm{~s}$ (extension). The $2^{-\Delta \Delta \mathrm{CT}} \operatorname{method}\left({ }^{*}\right)$ was used to calculate relative changes in gene expression determined from real-time quantitative PCR experiments. We used GAPDH as an internal control for quantitative PCR.

\section{HC-gp-39 Serum ELISA}

HC-gp-39 levels were determined for the serum samples using an HC-gp-39 ELISA kit (Metra YKL40, Quidel Corporation, San Diego, USA) according to the manufacturer's protocol and using a BioKinetics Reader (EL312e, BIO-TEK instruments Inc., Winooski, VT, USA).

\section{Statistical Analysis}

The Mann-Whitney $U$-test was used to compare the mean serum HC-gp-39 values in patients with pancreatic cancer, chronic pancreatitis, and those without pancreatic disease. Descriptive statistical values and plots of the concentration of HC-gp-39 in serum were generated using the SPSS 11.5 for Windows software program.

\section{Results}

RNA Isolation from Frozen Tissue Samples Obtained by Laser Capture Microdissection

RNA was successfully extracted from all nine microdissected samples from frozen tissue sections and RNA quality was determined by RT-PCR analysis of $G A P D H$ prior to further analysis. RNA samples were subjected to linear amplification. The total amount of cRNA after the first round of linear amplification ranged from 1.0 to $3.7 \mu \mathrm{g}$ (mean, $1.6 \mu \mathrm{g}$ ), and the final amount of cRNA after the second round amplification ranged from 22.5 to $186.0 \mu \mathrm{g}$ (mean, $120.5 \mu \mathrm{g}$ ). Hybridization of the amplified RNA to the Human Genome U133A chips revealed mean $3^{\prime} / 5^{\prime}$ ratios for housekeeping genes (GAPDH/M33197) of 5.3 in the NP-parenchyma samples, 8.5 in the CP-parenchyma samples, and 8.0 in the PC-parenchyma samples. The mean background signal intensities were 42.4 in the NP-parenchyma samples, 47.3 in the CP-parenchyma samples, and 44.6 in the PC-parenchyma samples.

\section{Identification of Genes Differentially Expressed in Pancreatic Parenchyma}

A total of 128 gene fragments was identified as overexpressed in the parenchyma of pancreatic cancer compared to that of normal pancreas, of which 41 corresponded to 'expressed sequence tags (ESTs)'. (The criteria used to define a gene as overexpressed was expressed >three-fold higher than in normal parenchyma, with a present call in at least one of the three tissues analyzed). Genes that were highly expressed included HIP/PAP (increased 130.6-fold), LTF (increased 40.6-fold), HC-gp39 (increased 18.2-fold), Regenerating islet-derived 1 beta (REG1B) (increased 17.3-fold), osteopontin (nephropontin) (increased 13.1-fold), and TLR3 
Table 1 Genes overexpressed in acinar tissue adjacent to infiltrating pancreatic cancer

\begin{tabular}{|c|c|c|c|}
\hline \multirow[t]{2}{*}{ Gene bank } & \multirow[t]{2}{*}{ Gene name } & \multicolumn{2}{|c|}{$P C$ (fold change) compared to } \\
\hline & & $N P-P$ & $C P-P$ \\
\hline (1) NM_002580.1 & Pancreatitis-associated protein (HIP/PAP) ${ }^{\mathrm{a}}$ & 130.6 & 9.9 \\
\hline (2) NM 002343.1 & Lactotransferrin (LTF) ${ }^{\mathrm{a}}$ & 40.6 & 3.1 \\
\hline (3) M80927.1 & Human Cartilage glycoprotein-39 (HC-gp39)a & 18.2 & 6.8 \\
\hline (4) NM_006507.1 & $\begin{array}{l}\text { Regenerating islet-derived } 1 \text { beta (pancreatic } \\
\text { stone protein, pancreatic thread protein) (REG1B) }\end{array}$ & 17.3 & 7.1 \\
\hline (5) NM_006508.1 & $\begin{array}{l}\text { Rat regenerating islet-derived-like, human } \\
\text { homolog (REGL) }\end{array}$ & 14.8 & 15.2 \\
\hline (6) NM_018295.1 & $\begin{array}{l}\text { Homo sapiens hypothetical protein FLJ11000 } \\
\text { (FLJ11000) }\end{array}$ & 10.7 & 8.5 \\
\hline (7) NM_018234.1 & $\begin{array}{l}\text { Homo sapiens hypothetical protein FLJ10829 } \\
\text { (FLJ10829) }\end{array}$ & 7.7 & 3.6 \\
\hline (8) NM_021871.1 & $\begin{array}{l}\text { Fibrinogen, A alpha polypeptide (FGA), } \\
\text { transcript variant alpha }\end{array}$ & 7.3 & 8.5 \\
\hline (9) NM_020997.1 & Left-right determination, factor B (LEFTB) & 6.7 & 4.2 \\
\hline (10) NM__o01085.2 & $\begin{array}{l}\text { Serine (or cysteine) proteinase inhibitor, clade A } \\
\text { (alpha-1antiproteinase, antitrypsin), member } 3 \\
\text { (SERPINA3) }\end{array}$ & 6.2 & 3.6 \\
\hline (11) NM_000715.1 & $\begin{array}{l}\text { Complement component 4-binding protein, } \\
\text { alpha (C4BPA) }\end{array}$ & 5.6 & 4.1 \\
\hline (12) NM_001022.1 & Ribosomal protein S19 (RPS19) & 5 & 4.4 \\
\hline (13) NM_001871.1 & Carboxypeptidase B1 (tissue) (CPB1) & 5 & 3.3 \\
\hline (14) NM_003761.1 & $\begin{array}{l}\text { Vesicle-associated membrane protein } 8 \\
\text { (endobrevin) (VAMP8) }\end{array}$ & 4.6 & 6.6 \\
\hline (15) BC006134.1 & Homo sapiens, clone MGC:13053 & 4.3 & 11.3 \\
\hline (16) NM_015849.1 & Pancreatic elastase IIB (LOC51032) & 3.8 & 6.7 \\
\hline (17) NM_006994.2 & Butyrophilin, subfamily 3, member A3 (BTN3A3) & 3.6 & 4.3 \\
\hline (18) NM_000096.1 & Ceruloplasmin (ferroxidase) (CP) & 3.5 & 3.3 \\
\hline (19) NM_017422.2 & Calmodulin-like skin protein (CLSP) & 3.3 & 4.3 \\
\hline (20) AB018580.1 & $\begin{array}{l}\text { hluPGFS ( } 3 \text {-alpha hydroxysteroid } \\
\text { dehydrogenase, type II) }\end{array}$ & 3.3 & 3.6 \\
\hline
\end{tabular}

${ }^{\mathrm{a}}$ The results were confirmed by quantitative RT-PCR.

CP-P: parenchyma adjacent to chronic pancreatitis; NP-P: parenchyma from normal pancreas; PC: pancreatic cancer.

(increased 10.2-fold). Of the 87 overexpressed gene fragments (excluding ESTs), 20 gene fragments were also overexpressed in the parenchyma of pancreatic cancer compared to the parenchyma of chronic pancreatitis (using the same above-mentioned criteria) (Table 1). These 20 genes included HIP/PAP, LTF, HC-gp39, and C4BPA.

A total of 202 genes was overexpressed in the parenchyma of chronic pancreatitis compared to that of normal pancreas ( $>$ three-fold, at least 1 'Present' call in CP-parenchyma), of which 101 corresponded to 'ESTs'. This list included several genes, such as $C D 58, C D 79 B$, and $L C P 2$, considered to be derived from inflammatory cells and fibrinogen, which was probably derived from small amounts of fibrous stroma microdissected along with pancreatic parenchyma. Fibrinogen is present in the tumor-related stroma where it may contribute to desmoplasia formation. ${ }^{7-10}$

In all, 39 known genes were increased in both the pancreatic cancer parenchyma and the chronic pancreatitis parenchyma relative to normal pancreatic parenchyma (Table 2). Many of these genes were related to the host response to environmental stress (TLR 3, glutathione peroxidase, SCN9A, etc), to the regulation of cell proliferation $(L T F)$, or to apoptosis (GAS 1).

In all, 77 genes were underexpressed in the pancreatic cancer parenchyma compared to that of normal pancreas, of which 27 corresponded to 'ESTs'. This list included STAT-induced STAT inhibitor-2 (decreased, 9.2-fold), cellular growthregulating protein (decreased, 7.8 -fold), and activating transcription factor 3 (decreased, 5.3-fold). The significance of these reductions in parenchymal gene expression is not known.

\section{Comfirmation of Differential Expression of Selected Genes}

We performed quantitative RT-PCR and immunohistochemistry to confirm the expression patterns of several genes identified as overexpressed by oligonucleotide microarrays. Quantitative RT-PCR analyses of four randomly selected genes identified as overexpressed in PC-parenchyma relative to NP-parenchyma and CP-parenchyma were highly correlated with that of oligonucleotide microarray data (Figure 2). HIP/PAP was most highly expressed 
Table 2 Genes overexpressed in parenchyma adjacent to chronic pancreatitis and to infiltrating pancreatic cancer relative to normal pancreatic parenchyma

\begin{tabular}{|c|c|c|c|}
\hline \multirow[t]{2}{*}{ Gene bank } & \multirow[t]{2}{*}{ Gene name } & \multicolumn{2}{|c|}{${ }^{*}$ Fold change } \\
\hline & & $C P-P$ & $P C-P$ \\
\hline (1) NM_002580.1 & Pancreatitis-associated protein (HIP/PAP) & 13.2 & 130.6 \\
\hline (2) NM_002343.1 & Lactotransferrin (LTF) & 13.2 & 40.6 \\
\hline (3) BC005907.1 & $\begin{array}{l}\text { Similar to histamine } N \text {-methyltransferase, clone } \\
\text { MGC: } 14500\end{array}$ & 10.2 & 14.7 \\
\hline (4) BC005930.1 & $\begin{array}{l}\text { Similar to CD58 antigen, (lymphocyte function- } \\
\text { associated antigen 3), clone MGC: } 14538\end{array}$ & 7.5 & 14.7 \\
\hline (5) NM_014080.1 & Dual oxidase-like domains 2 (DUOX2) & 4.8 & 13.6 \\
\hline (6) M83248.1 & $\begin{array}{l}\text { Nephropontin (osteopontin, bone sialoprotein I, } \\
\text { early T-lymphocyte activation 1) }\end{array}$ & 5.3 & 13.1 \\
\hline (7) NM_003776.1 & $\begin{array}{l}\text { Nuclear localization signal deleted in } \\
\text { velocardiofacial syndrome (NLVCF) }\end{array}$ & 11.4 & 12.3 \\
\hline (8) NM_003082.1 & $\begin{array}{l}\text { Small nuclear RNA activating complex, } \\
\text { polypeptide } 1,43 \mathrm{kD} \text { (SNAPC1) }\end{array}$ & 11.7 & 11.5 \\
\hline (9) NM_016184.1 & $\begin{array}{l}\text { C-type (calcium dependent, carbohydrate- } \\
\text { recognition domain) lectin, superfamily member } \\
6 \text { (CLECSF6) }\end{array}$ & 7.5 & 10.6 \\
\hline (10) NM_003265.1 & Toll-like receptor 3 (TLR3) & 6.7 & 10.2 \\
\hline (11) NM_016548.1 & Golgi membrane protein GP73 (LOC51280) & 6.1 & 9.0 \\
\hline (12) NM_000581.1 & Glutathione peroxidase 1 (GPX1) & 10.3 & 8.8 \\
\hline (13) NM_001866.1 & Cytochrome $c$ oxidase subunit VIIb (COX7B) & 9.0 & 8.1 \\
\hline (14) NM_002977.1 & $\begin{array}{l}\text { Sodium channel, voltage-gated, type IX, alpha } \\
\text { polypeptide (SCN9A) }\end{array}$ & 7.8 & 7.8 \\
\hline (15) NM_018412.2 & $\begin{array}{l}\text { Suppression of tumorigenicity } 7 \text { (ST7), transcript } \\
\text { variant a }\end{array}$ & 6.4 & 7.2 \\
\hline (16) NM_002048.1 & Growth arrest-specific 1 (GAS1) & 9.2 & 6.9 \\
\hline (17) D55696.1 & Cysteine protease & 8.8 & 6.4 \\
\hline (18) NM_014666.1 & KIAA0171 gene product (KIAA0171) & 14.4 & 6.2 \\
\hline (19) NM_006895.1 & Histamine $N$-methyltransferase (HNMT) & 5.8 & 5.5 \\
\hline (20) NM_017577.1 & $\begin{array}{l}\text { Homo sapiens hypothetical protein } \\
\text { DKFZp434C0328 (DKFZp434C0328) }\end{array}$ & 4.9 & 5.5 \\
\hline (21) L03411.1 & Human RD protein (RD) & 3.7 & 5.4 \\
\hline (22) NM_006731.1 & $\begin{array}{l}\text { Fukuyama type congenital muscular dystrophy } \\
\text { (FCMD) }\end{array}$ & 7.4 & 5.1 \\
\hline (23) NM_003595.1 & Tyrosylprotein sulfotransferase 2 (TPST2) & 3.1 & 5.1 \\
\hline (24) AF151867.1 & CGI-109 protein & 9.5 & 5.0 \\
\hline (25) NM_015474.1 & DKFZP564A032 protein (DKFZP564A032) & 5.6 & 4.8 \\
\hline (26) NM_014897.1 & KIAA0924 protein (KIAA0924) & 7.4 & 4.4 \\
\hline (27) NM_005722.1 & $\begin{array}{l}\text { Human ARP2 (actin-related protein 2, yeast) } \\
\text { homolog (ACTR2) }\end{array}$ & 3.7 & 4.1 \\
\hline (28) NM_004038.1 & Amylase, alpha 1A; salivary (AMY1A) & 5.3 & 4.1 \\
\hline (29) NM_006324.1 & Craniofacial development protein 1 (CFDP1) & 3.4 & 4 \\
\hline (30) NM_005873.1 & Regulator of G-protein signalling 19 (RGS19) & 5.5 & 3.8 \\
\hline (31) NM_000277.1 & Phenylalanine hydroxylase (PAH) & 9.1 & 3.8 \\
\hline (32) NM_004342.2 & Caldesmon 1 (CALD1) & 5.2 & 3.7 \\
\hline (33) NM_013943.1 & Chloride intracellular channel 4 (CLIC4) & 5.5 & 3.6 \\
\hline (34) M87789.1 & $\begin{array}{l}\text { Human (hybridoma H210) anti-hepatitis A IgG } \\
\text { variable region, constant region, } \\
\text { complementarity-determining regions }\end{array}$ & 6.6 & 3.6 \\
\hline (35) NM_024614.1 & $\begin{array}{l}\text { Homo sapiens hypothetical protein FLJ13197 } \\
\text { (FLJ13197) }\end{array}$ & 5.0 & 3.5 \\
\hline (36) NM_007358.1 & Putative DNA binding protein (M96) & 4.5 & 3.4 \\
\hline (37) AF213459.1 & Ephrin receptor EPHA3 complete form (EPHA3) & 7.8 & 3.3 \\
\hline (38) NM_002296.1 & Lamin B receptor (LBR) & 3.7 & 3.2 \\
\hline (39) NM_001482.1 & $\begin{array}{l}\text { Glycine amidinotransferase (L-arginine:glycine } \\
\text { amidinotransferase) (GATM) }\end{array}$ & 4.7 & 3.1 \\
\hline
\end{tabular}

CP-P: parenchyma adjacent to chronic pancreatitis; PC-P: parenchyma adjacent to infiltrating pancreatic cancer.

in PC-parenchyma; however, increased expression was also observed in CP-parenchyma (Figure 2 and Table 1). Lactoferrin had an expression pattern in the three groups that was similar to that of HIP/PAP. Quantitative RT-PCR demonstrated clear differences in the expression of HCgp39 and C4BPA in the parenchyma of PC compared to that of CP-parenchyma (Figure 2).

Next, we performed immunohistochemical analysis of five proteins whose gene expression patterns demonstrated increased expression in pancreatic cancer parenchyma. Frozen sections were used to 

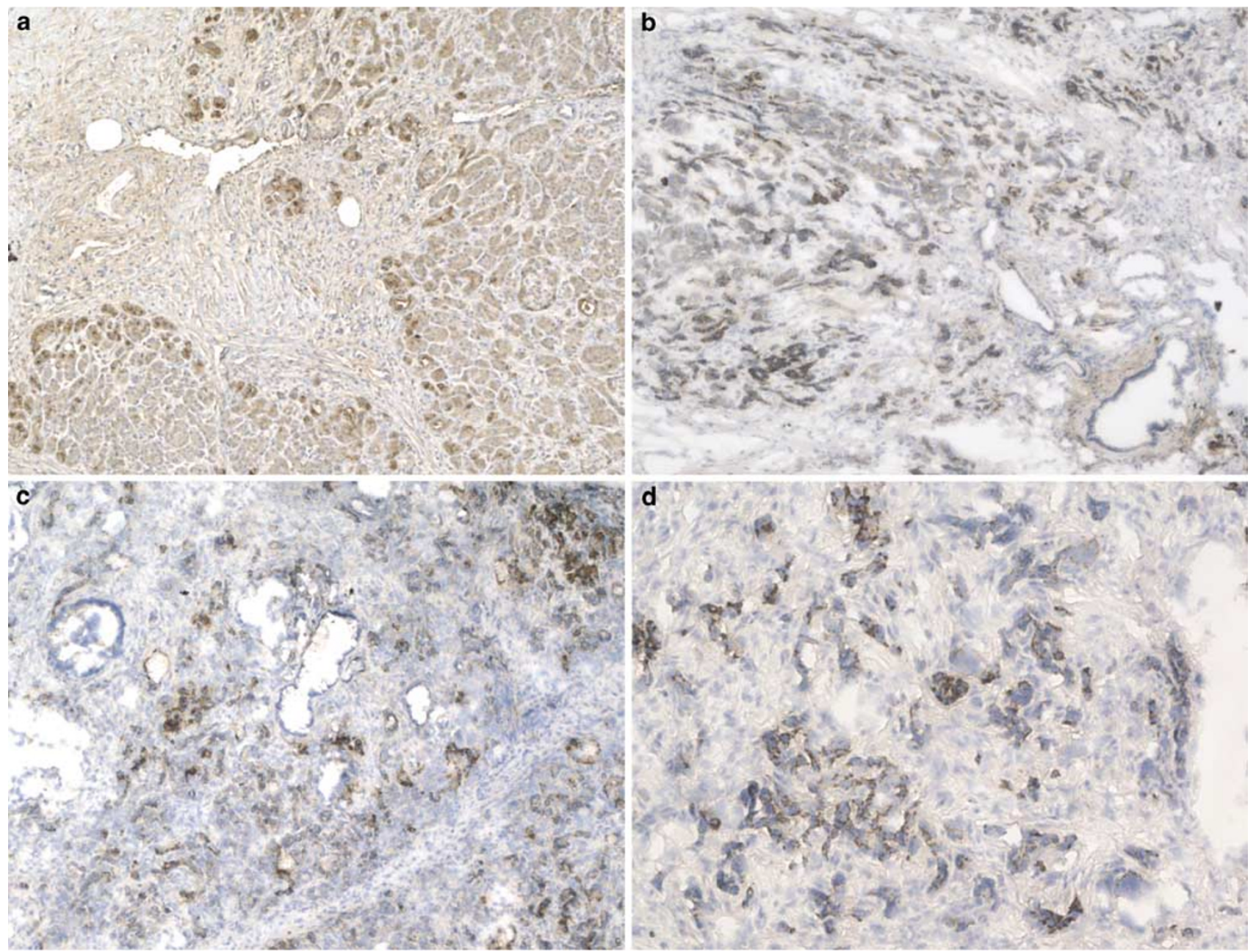

Figure 3 Immunohistochemical validation of overexpressed genes. Shown are representative paraffin (a), or frozen (b-d) sections of pancreatic tissues labeled with antibody against HIP/PAP protein (a), lactoferrin (b), GAS1 (c), and TLR3 (d), magnification 1/100.

analyze three proteins (LTF, GAS1, and TLR3) and paraffin sections for HIP/PAP and YKL-40 (HC-gp39) protein analysis. As expected, HIP/PAP expression was higher in the acinar tissue adjacent to infiltrating adenocarcinoma ${ }^{6}$ (Figure 3 ). This was also true for YKL-40 expression (not shown). YKL40 was expressed modestly in normal acinar tissue, with more intense labeling in normal islets. YKL-40 labeling was more intense in acinar tissue adjacent to infiltrating pancreatic cancers, similar to that seen with HIP/PAP expression. YKL-40 was also expressed in some but not all pancreatic ductal adenocarcinomas tested (four of five), but was not expressed in one intraductal papillary mucinous neoplasm. For GAS1, weak cytoplasmic staining was seen diffusely in normal appearing acinar tissue and islet cells, with strong cytoplasmic staining observed only in atrophic and duct-like metaplastic acinar cells (Figure 3). This labeling pattern was also observed for TLR3 and LTF (Figure 3). In contrast, LTF, GAS1, and TLR3 labeling was absent or virtually absent in normal pancreatic duct, peritumoral fibroblasts, and in infiltrating pancreatic carcinoma cells.

\section{HC-gp-39 (YKL-40) Protein Levels in the Serum}

Since microarray and quantitative RT-PCR results demonstrated increased HC-gp-39 expression in the parenchyma of pancreatic cancers, we investigated whether HC-gp-39 could be used as a marker of pancreatic cancer. We determined HC-gp-39 levels in the serum of patients with pancreatic cancer and chronic pancreatitis, as well as in a group of disease

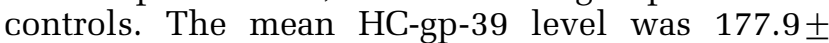
$28.1 \mathrm{ng} / \mathrm{ml}$ (mean \pm s.e.) in patients with pancreatic cancer $(n=40)$ and $(126.7 \pm 20.4 \mathrm{ng} / \mathrm{ml})$ in patients with non-neoplastic gastrointestinal diseases $(n=46)$. Of the 46 patients, 28 with non-neoplastic diseases had chronic pancreatitis and this subgroup had an HC-gp-39 level of $141.9 \pm 28.2 \mathrm{ng} / \mathrm{ml}$ (Figure 4). Serum HC-gp-39 levels were significantly higher in patients with pancreatic cancer $(n=40)$ than in patients 
786

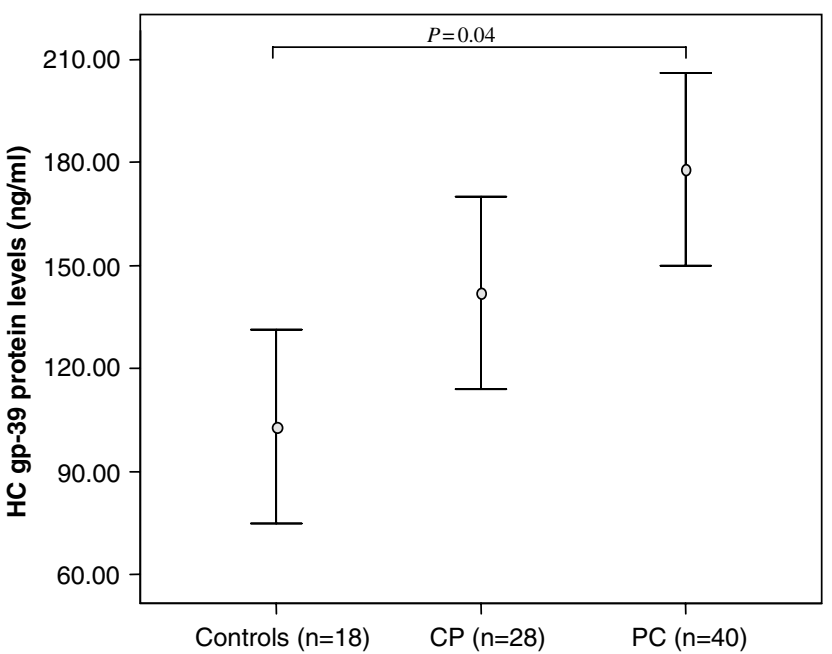

Figure 4 HC-gp-39 protein levels in serum. The mean HC-gp-39 protein concentration \pm standard error of each study group: $103 \pm 28.3 \mathrm{ng} / \mathrm{ml}$ in disease controls (controls), $141.9 \pm 28.2 \mathrm{ng} / \mathrm{ml}$ in patients with chronic pancreatitis (CP), and $177.9 \pm 28.1 \mathrm{ng} / \mathrm{ml}$ in patients with pancreatic cancer (PC).

without pancreatic disease $(n=18) \quad(103.0 \pm$ $28.3 \mathrm{ng} / \mathrm{ml}, P=0.044$ ), although there was no significant difference in gp-39 levels between those with pancreatic cancer and those with chronic pancreatitis. To determine if patients with pancreatic cancer and pancreatitis had higher HC-gp-39 levels than normal controls, we repeated the ELISA on an independent sample of patients and controls. We compared 50 patients each with chronic pancreatitis and pancreatic cancer, and healthy controls. The results were similar to the first patient groups. The mean HC-gp-39 level in patients with pancreatic cancer was $155 \pm 103 \mathrm{ng} / \mathrm{ml}$, for patients with pancreatitis it was $136 \pm 112 \mathrm{ng} / \mathrm{ml}$, and for healthy controls, it was $116 \pm 98$. There was a significant difference in HC-gp-39 levels between patients with pancreatic cancer and the controls $(P<0.05)$ and between those with pancreatitis and healthy controls $(P<0.05)$. Although levels of HC-gp39 were somewhat higher in patients with pancreatic cancer than in those with chronic pancreatitis, this was not statistically significant (data not shown).

\section{Discussion}

In this study, we have identified several genes that are overexpressed in the pancreatic parenchyma adjacent to infiltrating pancreatic ductal adenocarcinoma and in the setting of chronic pancreatitis. Thus, 20 genes including HIP/PAP, lactoferrin, and HC-gp-39 were more abundantly expressed in the acinar tissue surrounding infiltrating pancreatic cancers than in acinar tissue adjacent to areas of chronic pancreatitis. Apart from these genes, the expression patterns of acinar tissue adjacent to infiltrating pancreatic cancers were similar to those found adjacent to areas of chronic pancreatitis. We have previously demonstrated that one of these acinar proteins, HIP/PAP, is significantly elevated in the serum and pancreatic juice of patients with pancreatic cancer ${ }^{6}$ and in this study, we have demonstrated that another protein expressed by acinar cells, HC-gp-39, is elevated in the serum of patients with pancreatic cancer compared to patients with nonpancreatic gastrointestinal diseases (such as gastritis), to patients with abnormal liver function tests, and to healthy controls. Patients with chronic pancreatitis had levels of HC-gp-39 almost as high as those with pancreatic cancer, and were also significantly higher than those in healthy controls.

The mechanism and biological significance of elevated HIP and of HC-gp-39 in peritumoral acinar tissues is not known. HC-gp-39 is thought to function as a growth factor for human connective tissue cells, ${ }^{11}$ as a potent migration factor for endothelial cells. ${ }^{12}$ Since HC-gp-39 is a growth factor in several tissues and has been shown to act through AKT pathways, ${ }^{13}$ it is possible that HC-gp39 release by peritumoral acini could promote pancreatic cancer growth.

Our analysis of peritumoral gene expression also identified several genes that have been previously identified as overexpressed in primary pancreatic cancer tissues. For example, osteopontin, a secreted glycoprotein expressed prominently in bone and by lining epithelial cells, was first identified as overexpressed in pancreatic cancers by oligonucleotide microarrays $^{14}$ and we have recently found that osteopontin protein levels are significantly elevated in patients with resectable pancreatic adenocarcinoma compared to healthy controls $(P<0.001){ }^{15}$ Other interesting genes identified as overexpressed in the parenchyma of pancreatic cancer and chronic pancreatitis are lactoferrin and fibrinogen. Lactoferrin is a multifunctional member of the transferrin family of non-heme iron-binding glycoproteins. Lactoferrin is found at the mucosal surface where it functions as a prominent component of the first line of host defense against infection and inflammation. ${ }^{16}$ The protein is also an abundant component of the specific granules of neutrophils and can be released into the serum upon neutrophil degranulation. ${ }^{16}$ Elevations of lactoferrin have previously been reported in the pancreatic juice of patients with chronic calcifying pancreatitis and/or autoimmunerelated pancreatitis. ${ }^{17-20}$ Interestingly, in experimental studies, lactoferrin has been shown to inhibit the growth of some solid tumors such as colon, esophagus, and lung tumors. ${ }^{21,22}$ Interestingly, stool lactoferrin has been shown to be a sensitive marker of intestinal inflammation in patients with intestinal tract symptoms and is being used in clinical practice to identify patients with intestinal tract inflammation. ${ }^{23}$ Our results suggest that the detection of lactoferrin protein levels in the stool might also be a practical noninvasive screening test for pancreatic inflammation or cancer invasion among patients with suspected pancreatic disease. However, since 
stool lactoferrin is a feature of many other luminal gastrointestinal diseases, stool lactoferrin measurement may be too nonspecific for diagnostic use, even among patients with suspected pancreatic disease.

In summary, we have identified numerous genes expressed in the non-neoplastic parenchyma adjacent to infiltrating pancreatic carcinoma and chronic pancreatitis. Molecular alterations occurring within the pancreatic parenchyma as a result of infiltrating pancreatic ductal adenocarcinoma can be helpful predictors of the presence of pancreatic cancer.

\section{Acknowledgements}

This work was supported by the SPORE in Gastrointestinal Cancer (CA62924), the Michael Rolfe Foundation, and Deutsche Krebshilfe (JK).

\section{References}

1 Klöppel GHR, Longnecker DS, Adler G, et al. Ductal adenocarcinoma of the pancreas. In: LA HSaA (ed). Pathology \& Genetics, Tumours of the Digestive System, World Health Organization of Tumours. IARC Press: Lyon, 2000, pp 221-230.

2 Iacobuzio-Donahue CA, Ryu B, Hruban RH, et al. Exploring the host desmoplastic response to pancreatic carcinoma: gene expression of stromal and neoplastic cells at the site of primary invasion. Am J Pathol 2002;160:91-99.

3 Sato N, Fukushima N, Maehara N, et al. SPARC/ osteonectin is a frequent target for aberrant methylation in pancreatic adenocarcinoma and a mediator of tumor-stromal interactions. Oncogene 2003;22:50215030.

4 Frossard JL, Rubbia-Brandt L, Wallig MA, et al. Severe acute pancreatitis and reduced acinar cell apoptosis in the exocrine pancreas of mice deficient for the Cx32 gene. Gastroenterology 2003;124:481-493.

5 Ryu B, Jones J, Hollingsworth MA, et al. Invasionspecific genes in malignancy: serial analysis of gene expression comparisons of primary and passaged cancers. Cancer Res 2001;61:1833-1838.

6 Rosty C, Christa L, Kuzdzal S, et al. Identification of hepatocarcinoma-intestine-pancreas/pancreatitis-associated protein I as a biomarker for pancreatic ductal adenocarcinoma by protein biochip technology. Cancer Res 2002;62:1868-1875.

7 Costantini V, Zacharski LR, Memoli VA, et al. Fibrinogen deposition without thrombin generation in primary human breast cancer tissue. Cancer Res 1991;51: 349-353.

8 Wojtukiewicz MZ, Rucinska M, Zacharski LR, et al. Localization of blood coagulation factors in situ in pancreatic carcinoma. Thromb Haemost 2001;86: 1416-1420.

9 Preston T, Slater C, McMillan DC, et al. Fibrinogen synthesis is elevated in fasting cancer patients with an acute phase response. J Nutr 1998;128:1355-1360.

10 Simpson-Haidaris PJ, Rybarczyk B. Tumors and fibrinogen. The role of fibrinogen as an extracellular matrix protein. Ann NY Acad Sci 2001;936:406-425.

11 De Ceuninck F, Gaufillier S, Bonnaud A, et al. YKL-40 (cartilage gp-39) induces proliferative events in cultured chondrocytes and synoviocytes and increases glycosaminoglycan synthesis in chondrocytes. Biochem Biophys Res Commun 2001;285:926-931.

12 Malinda KM, Ponce L, Kleinman HK, et al. Gp38k, a protein synthesized by vascular smooth muscle cells, stimulates directional migration of human umbilical vein endothelial cells. Exp Cell Res 1999; 250:168-173.

13 Recklies AD, White C, Ling $H$. The chitinase 3-like protein human cartilage glycoprotein 39 (HC-gp39) stimulates proliferation of human connective-tissue cells and activates both extracellular signal-regulated kinase- and protein kinase B-mediated signalling pathways. Biochem J 2002;365:119-126.

14 Iacobuzio-Donahue CA, Maitra A, Shen-Ong GL, et al. Discovery of novel tumor markers of pancreatic cancer using global gene expression technology. Am J Pathol 2002;160:1239-1249.

15 Koopmann JFN, Jain A, Maitra A, et al. Evaluation of osteopontin as biomarker for pancreatic adenocarcinoma. Cancer Epidemiol Biomarkers Prev 2004;13: 487-491.

16 Ward PP, Uribe-Luna S, Conneely OM. Lactoferrin and host defense. Biochem Cell Biol 2002;80:95-102.

17 Estevenon JP, Sarles H, Figarella C. Lactoferrin in the duodenal juice of patients with chronic calcifying pancreatitis. Scand J Gastroenterol 1975;10:327-330.

18 Hayakawa T, Harada H, Noda A, et al. Lactoferrin in pure pancreatic juice in chronic pancreatitis. Am J Gastroenterol 1983;78:222-224.

19 Hayakawa T, Naruse S, Kitagawa M, et al. Pancreatic stone protein and lactoferrin in human pancreatic juice in chronic pancreatitis. Pancreas 1995;10: 137-142.

20 Okazaki K, Uchida K, Ohana M, et al. Autoimmunerelated pancreatitis is associated with autoantibodies and a Th1/Th2-type cellular immune response. Gastroenterology 2000;118:573-581.

21 Tsuda H, Sekine K, Fujita K, et al. Cancer prevention by bovine lactoferrin and underlying mechanisms-a review of experimental and clinical studies. Biochem Cell Biol 2002;80:131-136.

22 Ushida Y, Sekine K, Kuhara T, et al. Possible chemopreventive effects of bovine lactoferrin on esophagus and lung carcinogenesis in the rat. Jpn J Cancer Res 1999;90:262-267.

23 Kane SV, Sandborn WJ, Rufo PA, et al. Fecal lactoferrin is a sensitive and specific marker in identifying intestinal inflammation. Am J Gastroenterol 2003;98: 1309-1314. 